\title{
Impact of some intravenously administered drügs (paracetamol, hydrocortisone, dexamethasone and amikacin) on coagulation hemostasis (in vitro evaluation study)
}

\author{
Ausama Ayob Jaccobํㅜ, Shaema Mohammed Ali Mohammed ${ }^{1}$, Zainab Najim Abdul-nabi ${ }^{1}$
}

\begin{abstract}
Background: Normally, the coagulation homeostasis prevents bleeding and retain the blood in the vascular system during periods of injury. Unfortunately, pathological factors, drugs or toxins could affect one or more stages of homeostasis mechanisms leading to bleeding or abnormal thrombi. Evaluation of prothrombin time is a favorable test for the screening of extrinsic coagulation mechanism whilst activated partial thromboplastin time measurement is a global coagulation screening method for intrinsic factor.

Material and Methods: Blood samples were withdrawn from healthy adults volunteers for clotting times measurements from collected plasma. The effect of paracetamol, hydrocortisone, dexamethasone, and amikacin at different concentrations on coagulation homeostasis was in vitro investigated and compared to control and positive control.

Results: High concentrations of all tested drugs except amikacin prolong significantly activated partial thromboplastin time, whilst the effect on the prothrombin time was conflicting.

Conclusions: Paracetamol, hydrocortisone, dexamethasone, and amikacin could prolong clotting time expressed in prolongation of activated partial thromboplastin time comparable to the anticoagulants drugs.
\end{abstract}

Keywords: coagulation, drugs, prothrombin time, clotting factors, in vitro

\section{INTRODUCTION}

The coagulation homeostasis could be thought of as complex cascading reactions involving the development of enzymes from precursors with the aid of cofactors, ions, and phospholipid surfaces were the final product was fibrin meshwork clot (1). Normally, such mechanisms prevent bleeding and retain the blood in the vascular system during periods of injury. Unfortunately, different pathophysiological processes may disrupt coagulation homeostasis lead to the development of abnormal thrombi in the blood vessels leading to circulatory disorders like deep-vein thrombosis, myocardial infarction, stroke, and pulmonary embolism (2). There are several causative factors, drugs or toxins could affect one or more stages of homeostasis mechanisms leading to bleeding or abnormal thrombi (3). Thus, coagulation homeostasis is ordinarily conserved in check by different physiological antithrombotic processes blanket substantially the entire coagulation cascade. Antithrombin, protein $\mathrm{C}$, and protein $\mathrm{S}$ wield their anticoagulants action by affecting and inhibiting clotting factors (4).

Evaluation of prothrombin time (PT) is a favorable test for the screening of extrinsic coagulation mechanism whilst APTT measurement is a global coagulation screening method for intrinsic factor assessment that considered as a common pathway of the coagulation system. PT has been used to monitor and follow up on patient's response to anticoagulant therapy. However, due to PT is fluctuating depending on thromboplastin utilized in lab assays, International Normalized Ratio (INR) is presently the accepted gold standard for evaluation of warfarin therapy $(5,6)$.

1 College of Pharmacy, Basra University, Iraq.

Correspondence: Ausama Ayob Jaccob

College of Pharmacy, Basra University, Iraq.

Received: 5 Aug 2019, Accepted: 3 Oct 2019

E-mail: ausama1979@yahoo.com

(C) 2019 by the authors; licensee Modestum Ltd., UK. This article is an open access article distributed under the terms and conditions of the Creative Commons Attribution License (http://creativecommons.org/licenses/by/4.0/). 
Recently, drugs-induced coagulation disorders have been gained more attention in different articles to explain the direct or indirect thrombogenic effect of a variety of drugs consumed for the treatment of clinical disorders $(7,8)$.

Venous thrombosis is a common side effect of large number widely prescribed drugs, corticosteroids and contraceptive pills can lead to blood disorder in long term therapy $(9,10)$. Actually, multiple drugs may lead to unexpected increased risk of blood disorders, Girolami et al. clearly indicate and summarise the potential clinical significance of such problem, the authors focus on drugs with possible effect on coagulation cascade: gonadotropins, Cortisone, estradiol, nonsteroidal anti-inflammatory drugs, Clozapine antipsychotic, anabolic hormones, desmopressin, chemotherapeutic agents, in addition to other herbal and energy drinks. All these compound may lead to venous thrombosis as potential adverse effects (8).

On the contrary, sometimes drugs lead to unexpected bleeding tendency due to the reticence of platelet aggregation, coagulation hemostasis, and prolongation of PT (11). In a case report Dootson GM. et al found that oral isotretinoin may accelerate fibrinolysis and disturbed coagulation factors (12). Thus it is essential and mandatory to continuous monitoring of coagulation cascade very closely in patients with chronic use of drugs in the treatment of chronic illness (13). Actually, the present study was designed for in vitro evaluating the direct effect of some widely prescribed intravenous drugs on coagulation hemostasis explained by PT, APTT and INR.

\section{MATERIALS AND METHODS}

\section{Chemicals and Reagents}

Thrmpo Genex (USA), PT and APTT kits (BIOLABS France), Heparin (5000 unit/ml) Leo pharma Denmark), Paracetamol vial $10 \mathrm{mg} / \mathrm{ml}$ (PANPHARMA France), amikacin $(500 \mathrm{mg} / 2 \mathrm{ml}$ (Deva turkey), dexamethasone $8 \mathrm{mg} / 2 \mathrm{ml}$ (Deva turkey), and Hydrocortisone vial 100mg/2ml (Haemofarm company).

\section{Preparation of Plasma}

After obtaining written informed consent and ethical approval from the college of pharmacy, Basrah University, blood samples were withdrawn from healthy adults volunteers without a history of chronic diseases and free from chronic medications intake. All participants fasted overnight and they are medication-free for at least one week prior to blood collection. Blood collected into sodium citrate tube immediately centrifuged at $25000 \mathrm{r} / \mathrm{min}$ for $10 \mathrm{~min}$ according to manufacturer's instructions for PT and APTT measurements from collected plasma. The effect of paracetamol, hydrocortisone, dexamethasone, and amikacin at different concentrations on coagulation homeostasis was investigated in vitro consequently on day of blood collection without plasma freezing.

\section{Study Design (PT/INR and APTT Measurements)}

According to Félix-silva et al with slight modification (14), $0.1 \mathrm{ml}$ of 4 tested drugs with a series concentrations test samples as following: paracetamol $(50,10,5,1) \mathrm{mg} / \mathrm{ml}$, hydrocortisone $(50,25,5,1) \mathrm{mg} / \mathrm{ml}$, dexamethasone $(2,1,0.5)$

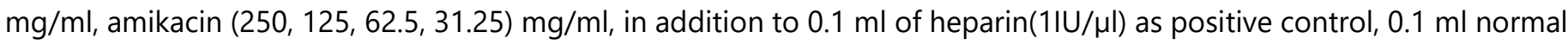
saline as negative control group and plasma alone (for INR measurement) were added to $0.9 \mathrm{ml}$ plasma then incubated for $10 \mathrm{~min}$ at 37c for subsequent PT and APTT analysis according to kit manufacturer instructions. Measurement of PT/INR and APTT reflect the direct effect of investigated drugs on extrinsic and intrinsic pathways respectively (15). For PT measurement, $200 \mu \mathrm{l}$ was pre-warmed for $15 \mathrm{~min}$ at $37^{\circ} \mathrm{C}$ and added to each tested samples and clotting time using coagulometer was recorded in seconds. APPT reagent was pre-warmed for $2 \mathrm{~min}$ at $37^{\circ} \mathrm{C}$ and added to the samples and clotting time recorded using coagulometer after adding Ca-solution kit. The INR values were calculated by dividing the sample PTover the mean normal PT ( geometric mean of the plasma only PT values) raised to the power of international sensitivity index ( $a$ function of the used thromboplastin reagent which is in our study equal to 1.65). This step was carried out in order to standardize the PT values and eliminate the differences resulted from using variable thromboplastin of different sources.

\section{Statistical Analysis}

The values were assessed statistically using ordinary one-way ANOVA analysis with Sidak's multiple comparisons test. Values are expressed as Mean \pm SD, Values with $P<0.05$ were considered significantly different. The statistical analysis was done by using software GraphPad Prism for Windows (version 7.0). 


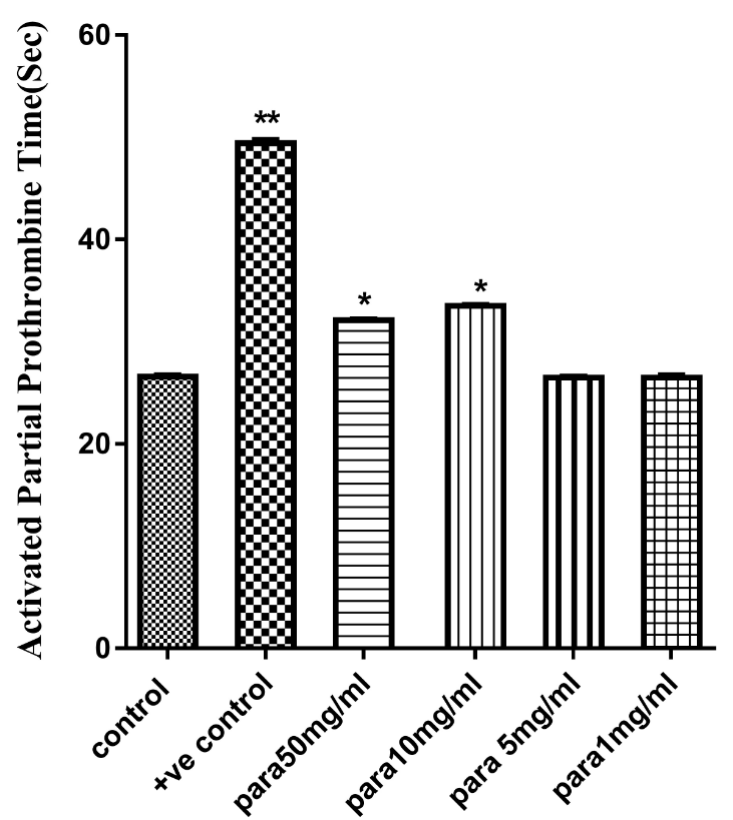

Figure 1: The effect of paracetamol in different concentrations on the activated partial thromboplastin time. ${ }^{*} p<00001$,

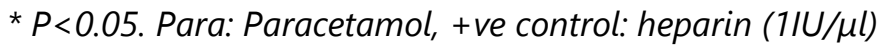

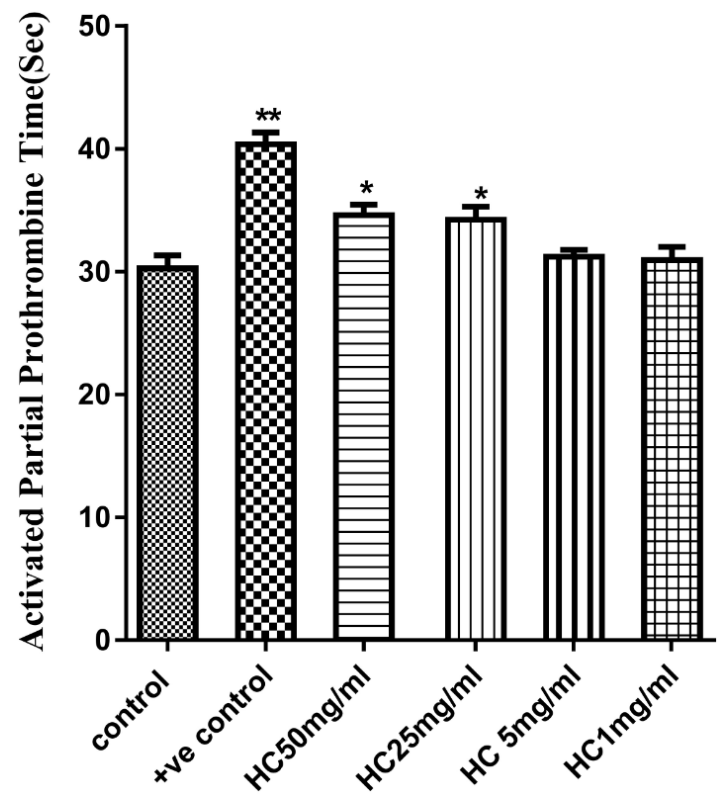

Figure 2: The effect of hydrocortisone in different concentrations on the activated partial thromboplastin time. ${ }^{* \star} p<00001$, ${ }^{*} P<0.05$. HC: hydrocortisone, +ve control: heparin $(1 / \mathrm{U} / \mu \mathrm{l})$

\section{RESULTS}

In the present study, PT/INR and APTT were utilized to assess the direct coagulation effect of common widely prescribed drugs for the treatment of different illness. Such drugs when administered by intravenous route may lead to direct interference with coagulation homeostasis could adversely affect physiological coagulation cascade.

As shown in Figure 1 paracetamol in 50 and $10 \mathrm{mg} / \mathrm{ml}$ prolong clotting time significantly in APTT test $(32.1 \pm 0.1$ and $33.5 \pm 0.1) \mathrm{sec}$ respectively versus it is level in control $(26.6 \pm 0.1) \mathrm{sec}$ demonstrating possible anticoagulant activity, such increment in APTT significantly less than that observed in +ve control group with addition of heparin (49.4 \pm 0.32$) \mathrm{sec}$. Whilst low concentrations of paracetamol show no significant effects compared to control.

Hydrocortisone in 50 and $25 \mathrm{mg} / \mathrm{ml}$ prolong significantly APTT clotting time $(34.6 \pm 0.85$ and $34.23 \pm 1.05) \mathrm{sec}$ respectively compared to control $(30.27 \pm 1.05)$ sec but such values are lower than that observed in +ve control group $40.37 \pm 0.95$. Lower concentrations of hydrocortisone 5 and $1 \mathrm{mg} / \mathrm{ml}$ showed no significant difference against control as summarized in Figure 2. 


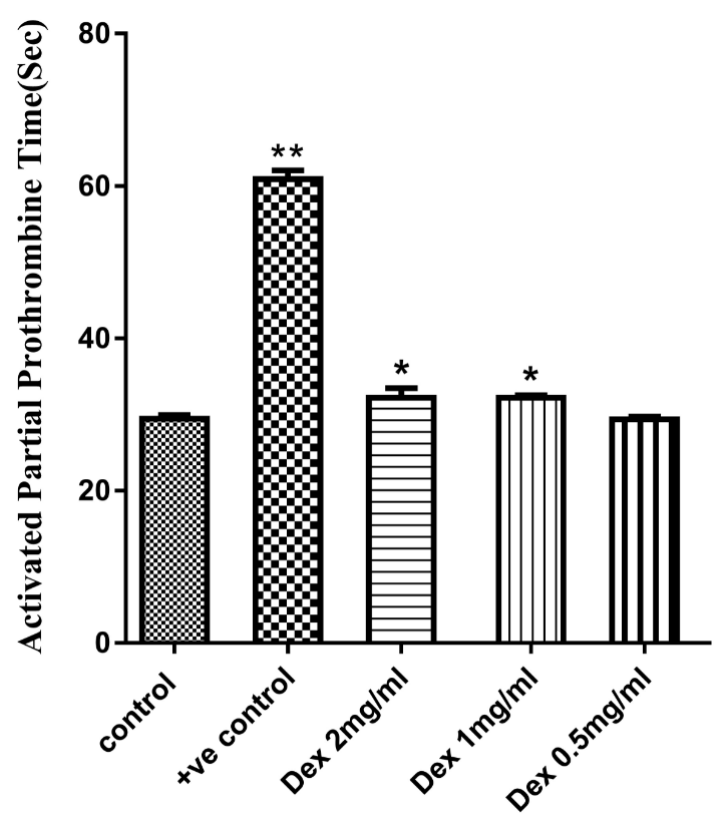

Figure 3: The effect of dexamethasone in different concentrations on the activated partial thromboplastin time. ** $p<00001$, * $P<0.05$. Dex: dexamethasone, +ve control: heparin $(1 / \mathrm{U} / \mu \mathrm{l})$

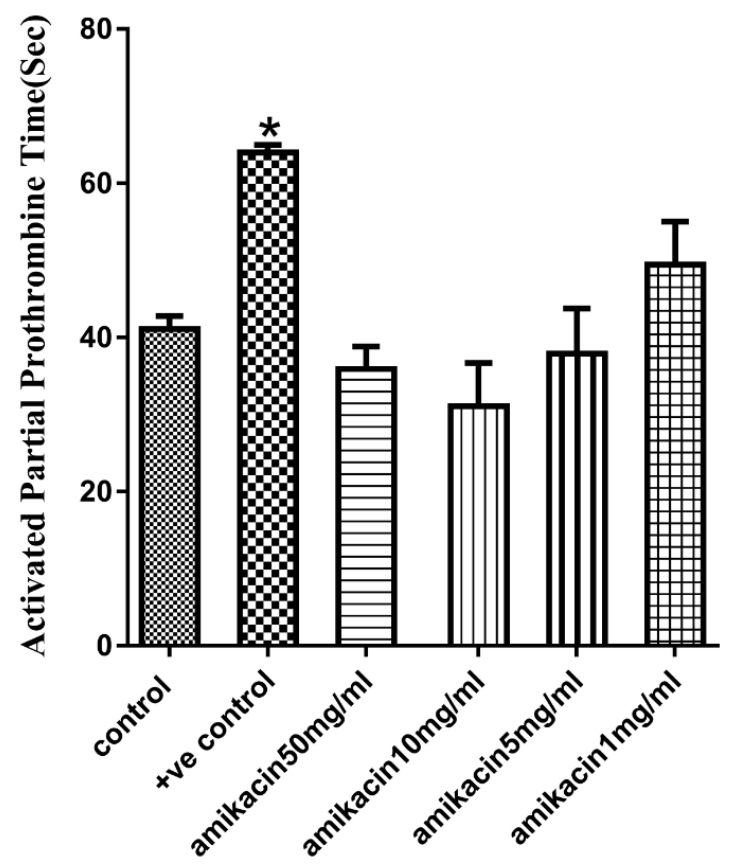

Figure 4: The effect of amikacin in different concentrations on the activated partial thromboplastin time, +ve control: heparin $(1 / U / \mu l)$

Regarding the effect of dexamethasone on APTT, 2 and $1 \mathrm{mg} / \mathrm{ml}$ prolong significantly clotting time (32.17 \pm 1.29 and $32.17 \pm 0.35) \mathrm{sec}$ respectively compared to control $(29.47 \pm 0.45) \mathrm{sec}$ whilst the highest APPT value observed in the +ve control group $(60.9 \pm 1.11) \mathrm{sec} .0 .5 \mathrm{mg} / \mathrm{ml}$ of dexamethasone showed no significant discrepancy was observed compared to the control group as appearing in Figure 3.

Figure 4 clearly summarized the direct effect of amikacin on APTT clotting time, no significant effect had been observed in all tested doses compared to control whilst the APPT level reach $63.97 \pm 1 \mathrm{sec}$ in the +ve control group and considered significantly high in comparison with remaining groups.

In order to get complete idea about the impact of drugs on the coagulation system, the PT test was performed and INR value was calculated. In regard to paracetamol and dexamethasone, no significant effect had been detected in all tested concentrations compared to control and +ve control groups as shown in Figures 5, 7 and in Table 1. On the other hand, the PT level in hydrocortisone $50 \mathrm{mg} / \mathrm{ml}$ concentration prolongs PT $(17.67 \pm 0.15 \mathrm{sec})$ as comparable to +ve control $(17.57 \pm 0.15 \mathrm{sec}) .25 \mathrm{mg} / \mathrm{ml}$ of hydrocortisone prolong PT $(16.67 \pm 0.15 \mathrm{sec})$ versus control but it is less significant 


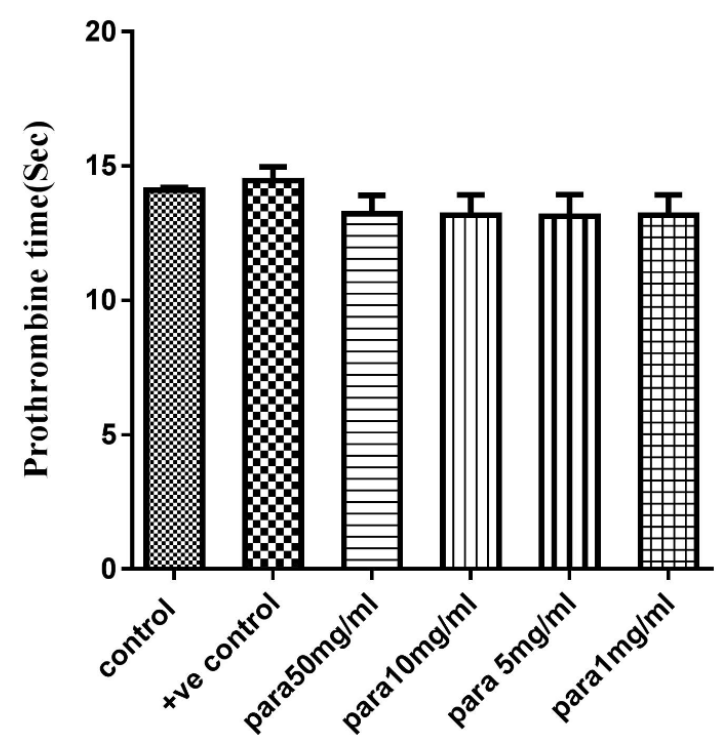

Figure 5: The effect of paracetamol in different concentrations on the prothrombin time. Para: Paracetamol, +ve control: heparin $(1 / U / \mu l)$

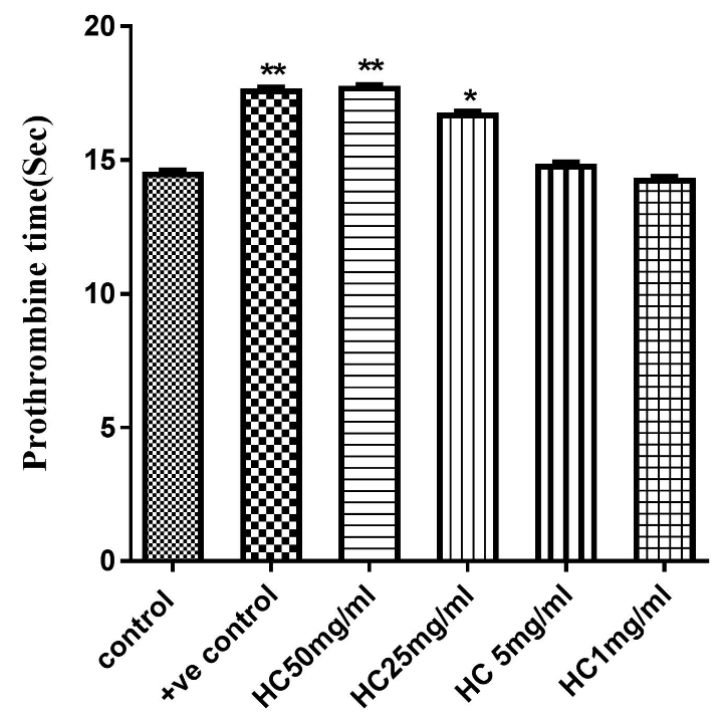

Figure 6: The effect of hydrocortisone in different concentrations on the prothrombin time. ${ }^{* *} p<00001,{ }^{*} P<0.05 . H C$ : hydrocortisone, +ve control: heparin $(1 / \mathrm{U} / \mu \mathrm{l})$

than that observed in +ve control as shown in Figure 6. Regarding the effect of hydrocortisone on INR, there was a significant increase in ratio in all evaluated concentrations except in $1 \mathrm{mg} / \mathrm{ml}$ compared to control, Such ratios were less significant compared to +ve control as shown in Table 1. The high concentration of amikacin $50 \mathrm{mg} / \mathrm{ml}$ prolongs PT significantly $17.47 \pm 1.6 \mathrm{sec}$ compared to control. Such effect seems to be as comparable to +ve control group $17.5 \pm 1.4$ whilst the remaining amikacin concentrations displayed no significant differences compared to control as indicated in Figure 8. Regarding INR, amikacin in all tested concentrations showed no significant effect compared to plasma as displayed in Table 1. 


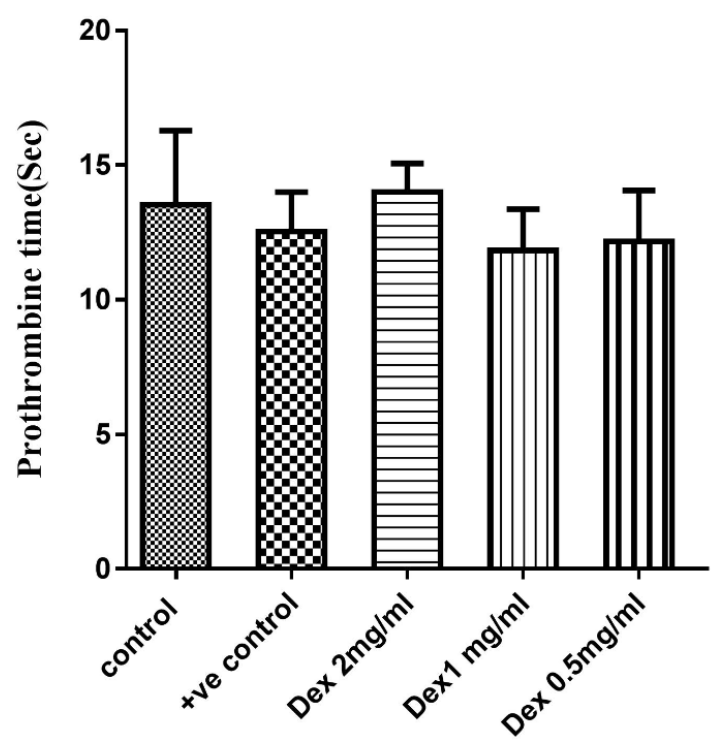

Figure 7: The effect of dexamethasone in different concentrations on prothrombin time. Dex: dexamethasone, + ve control: heparin $(1 / \mathrm{U} / \mu l)$

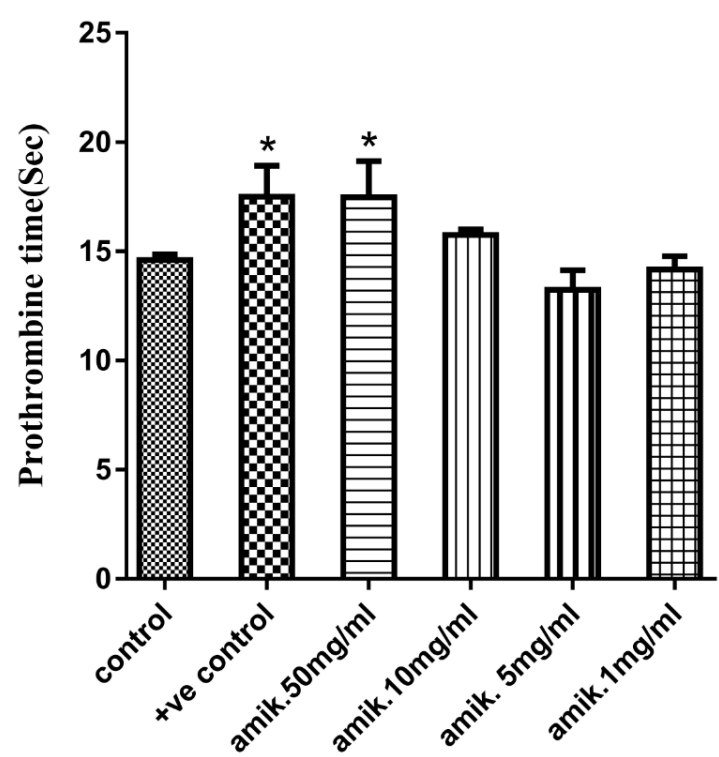

Figure 8: The effect of amikacin in different concentrations on prothrombin time, ${ }^{*} P<0.05+v e$ control: heparin $(1 / U / \mu l)$

Table 1: Effect of different concentrations of tested drugs on INR, values were expressed as Mean $\pm S D$, heparin as $+v e$ control and plasma as control. ${ }^{a}$ : represent significant difference compared to control. ${ }^{\boldsymbol{b}}$ : reperesent significant difference compared to +ve control. Para=Paracetamol, HC:Hydrocortisone, Dex: Dexamethasone, amik:amikacin

\begin{tabular}{|c|c|c|c|c|c|}
\hline \multirow{2}{*}{$\begin{array}{c}\begin{array}{c}\text { Control } \\
(\text { mean } \pm S D)\end{array} \\
\text { Plasma }\end{array}$} & \multirow{2}{*}{$\begin{array}{c}\begin{array}{c}\text { +ve Control } \\
\text { (mean } \pm \text { SD) }\end{array} \\
\text { Heparin } 1 \mathrm{IU} / \mu \mathrm{l}\end{array}$} & \multicolumn{4}{|c|}{ Tested drugs(mean $\pm S D)$} \\
\hline & & para50mg/ml & para10mg/ml & para $5 \mathrm{mg} / \mathrm{ml}$ & para $1 \mathrm{mg} / \mathrm{ml}$ \\
\hline $0.902 \pm 0.013$ & $1.067 \pm 0.06$ & $0.9217 \pm 0.078$ & $0.9117 \pm 0.091$ & $0.911 \pm 0.092$ & $0.9147 \pm 0.087$ \\
\hline plasma & Heparin $1 \mathrm{IU} / \mu \mathrm{I}$ & $\mathrm{HC} 50 \mathrm{mg} / \mathrm{ml}$ & $\mathrm{HC} 25 \mathrm{mg} / \mathrm{ml}$ & $\mathrm{HC} 5 \mathrm{mg} / \mathrm{ml}$ & $\mathrm{HC} 1 \mathrm{mg} / \mathrm{ml}$ \\
\hline $0.948 \pm 0.017$ & $1.2 \pm 0.02$ & $1.48 \pm 0.02 \mathrm{ab}$ & $1.343 \pm 0.02^{\text {ab }}$ & $1.1 \pm 0.02^{\mathrm{ab}}$ & $0.902 \pm 0.017^{\mathbf{b}}$ \\
\hline plasma & Heparin $1 \mathrm{IU} / \mu \mathrm{I}$ & Dex $2 \mathrm{mg} / \mathrm{ml}$ & Dex1 mg/ml & Dex $0.5 \mathrm{mg} / \mathrm{ml}$ & \\
\hline $0.9457 \pm 0.029$ & $0.8557 \pm 0.162$ & $1.027 \pm 0.126$ & $0.781 \pm 0.167$ & $0.82 \pm 0.203$ & \\
\hline plasma & Heparin $1 \mathrm{IU} / \mu \mathrm{I}$ & amik50mg/ml & amik10mg/ml & amik5mg/ml & amik1mg/ml \\
\hline $1.17 \pm 0.05$ & $1.46 \pm 0.194$ & $1.457 \pm 0.229$ & $1.223 \pm 0.0351$ & $0.922 \pm 0.103^{b}$ & $1.028 \pm 0.068^{b}$ \\
\hline
\end{tabular}

\section{DISCUSSION}

The high incidence of hemorrhagic and thrombotic disorders may be caused by the suboptimal use of drugs. This study was carried out for in vitro evaluation the direct coagulation effect of some drugs (paracetamol, dexamethasone, hydrocortisone, and amikacin) on hemostasis variables represented by PT and APTT. To avoid and raise knowledge about 
drug clotting factors interference in intravenously administered drugs may worse coagulation cascade which may lead to subsequent health issues.

In the present study, paracetamol at high concentrations prolongs clotting time expressed in PT and APTT significantly comparable to that observed by anticoagulants. It prevents the generation of prostaglandin mostly in the central nervous system this action by inhibition of COX-1 (16). However, peripheral side effects that occur with NSAIDs, like peptic ulcers and impaired coagulation hemostasis less appeared with acetaminophen (17). An explanation of our finding that an unstable toxic metabolite of paracetamol called $\mathrm{N}$-acetyl-para-benzoquinone imine (NAPQI) could slow up the function of vitamin $\mathrm{k}$ a processed cross-linked with glutathione depletion affecting clotting factors 2, 7, 9, and 10, which are important in blood coagulation process (18). The current study well correlates with the results of Dakheel $\mathrm{S}$ (19) invivo study, she reveals that long term paracetamol administration prolong PT and INR in those patients consumed paracetamol to relieve their headache. In fact, free radical generation and glutathione depletion are the exact explanation of our in vitro findings (20). Toxicologically, the intravenous administration of paracetamol has been linked with clinical mishaps including death. At this point there are restrictions on it is intravenous use compared to oral, intramuscular and rectal routs (21).

Regarding the effect of glucocorticoids on coagulation hemostasis is not resolved and still controversy. Some authors reported that corticosteroids (dexamethasone) lead to a procoagulant state in healthy individuals (22). Whilst others reported an increase in coagulation time by enhancing antithrombin 3 activity associated with decreased incidence and complication of abnormal clotting through nuclear receptors related mechanism (23). Actually, the results of the current study revealed that high doses of both H.C and dexamethasone increased significantly clotting time in APPT test compared to control. Such prolongation was not observed in the PT test except in high doses of H.C. this seems to be comparable to that observed in A. Colao et al. and S. Koutroumpi et al. were PT value usually maintained in Cushing patients or prolonged in certain circumstances $(24,25)$. Mechanistically, our findings need to be explained nonetheless only a few articles are available in this area. However, more than one study made a conclusion that corticosteroids decrease clotting time and increased the chance of thrombosis (26-28).

Corticosteroids (CS), such as prednisone, hydrocortisone and dexamethasone decreased the inflammation, and thus the thrombosis was reduced, although they were thrombi inducer in non-inflammatory diseases, like Cushing's syndrome this may be due to increases in factor 8 , fibrinogen, and von Willebrand factor, with decreased fibrinolysis which may not offset by increase the anticoagulant proteins, C and S (28). Indeed, our results regarding the effect of corticosteroids on coagulation hemostasis were not in agreement with an investigation in which the long-term administration of glucocorticoids lead to hypercoagulability in rats (29). All the available information about the effect of corticosteroids on clotting time are the results of in vivo animals and human studies. In the present study direct in vitro evaluation of corticosteroids effect on coagulation had been done. This is an important cause of controversy, but the logical explanation of our results is the relation and effect of CS on antithrombin3. This exactly means that CS affects the expression of the regulatory element of antithromine3. This came in tune with $\mathrm{D}$. Barettino et al., they suggest that management with CS might be a good pharmacological alternative to exogenous administered antithrombin3 formulation (23).

Regarding amikacin, we did not observe any significant effect on APTT clotting time whilst the only high concentration of amikacin prolong PT as compared to the +ve control group,

Generally, Amikacin could block the effects of ADP induced platelet aggregation by inhibiting the release and activation of fibrinogen or probably the inhibition of endogenous clotting factor as well (30). In contrast to our finding, another animal study in goats reported that intravenous amikacin in a dose of $10 \mathrm{mg} / \mathrm{kg}$ body weight was associated with increasing in the fibrinogen level and decreasing clotting time in the PT test (31). In conclusion, paracetamol, hydrocortisone, dexamethasone and amikacin in high concentration prolong clotting time significantly expressed in APTT without any effect observed in PT except for high doses of hydrocortisone and amikacin. In vivo studies are needed to support our in vitro finding that intravenously administered tested drugs could affect coagulation hemostasis.

\section{REFERENCES}

1. Cruz L. Clinical Hematology and Fundamentals of Hemostasis. Am J Clin Pathol., 2016;108(5):599.2-599. https://doi.org/10.1093/ajcp/108.5.599a

2. Choi JH, Kim DW, Park SE, Lee HJ, Kim KM, Kim KJ, et al. Anti-thrombotic effect of rutin isolated from Dendropanax morbifera Leveille. J Biosci Bioeng., 2015;120(2):181-6. https://doi.org/10.1016/j.jbiosc.2014.12.012 PMid:25777266 
3. Chai P, Babu K. Toxin-induced Coagulopathy. Emerg Med Clin North Am., 2014 Feb;32(1):53-78. https://doi.org/10.1016/j.emc.2013.10.001 PMid:24275169

4. Schafer Al, Levine MN, Konkle BA, Kearon C. Thrombotic disorders: diagnosis and treatment. Hematology Am Soc Hematol Educ Program, 2003;520-39. https://doi.org/10.1182/asheducation-2003.1.520 PMid:14633797

5. Favaloro EJ, Lippi G. The new oral anticoagulants and the future of haemostasis laboratory testing. Biochem Medica, 2012;329-41. Available at: http://www.biochemia-medica.com/en/journal/22/3/10.11613/BM.2012.035 PMid:23092064 PMCid:PMC3900050

6. Shetty S, Ghosh K, Mohanty D. Comparison of four commercially available activated partial thromboplastin time reagents using a semi-automated coagulometer. Blood Coagul Fibrinolysis, 2003 Jul;14(5):493-7. https://doi.org/10.1097/00001721-200307000-00011 PMid:12851537

7. Ramot Y, Nyska A, Spectre G. Drug-Induced Thrombosis: An Update. Drug Saf, 2013 Aug 3;36(8):585-603. Available at: http://link.springer.com/10.1007/s40264-013-0054-6 PMid:23640658

8. Girolami A, Cosi E, Tasinato V, Santarossa C, Ferrari S, Girolami B. Drug-Induced Thrombophilic or Prothrombotic States: An Underestimated Clinical Problem That Involves Both Legal and Illegal Compounds. Clin Appl Thromb, 2017 Oct 14;23(7):775-85. Available at: http://journals.sagepub.com/doi/10.1177/1076029616652724 PMid:27301402

9. Casonato A, Pontara E, Boscaro M, Sonino N, Sartorello F, Ferasin S, et al. Abnormalities of von Willebrand factor are also part of the prothrombotic state of Cushing's syndrome. Blood Coagul Fibrinolysis, 1999 Apr;10(3):14552. https://doi.org/10.1097/00001721-199904000-00006 PMid:10357009

10. Carter CJ. Oral contraceptives and thrombosis. Curr Opin Pulm Med, 2000 Jul;6(4):296-300. https://doi.org/10.1097/00063198-200007000-00008 PMid:10912636

11. Park TK, Shin SJ, Lee JH. Effect of Drugs Associated With Bleeding Tendency on the Complications and Outcomes of Transforaminal Epidural Steroid Injection. Clin Spine Surg, 2017 Mar;30(2):E104-10. https://doi.org/10.1097/BSD.0000000000000425 PMid:27623303

12. Dootson GM, Keidan J, Harper PL. The influence of isotretinoin upon fibrinolysis in patients with acne. $\mathrm{Br} J$ Dermatol, 2006 Jul 29;133(1):66-70. https://doi.org/10.1111/j.1365-2133.1995.tb02494.x PMid:7669643

13. Bettoli V, Pizzigoni S, Vasina S, Mancino A, Virgili A. Oral isotretinoin and haemophilia A. J Eur Acad Dermatology Venereol, 2004 Nov;18(6):718-20. https://doi.org/10.1111/j.1468-3083.2004.01062.x PMid:15482307

14. Félix-Silva J, Souza T, Camara RBBG, Cabral B, Silva-Júnior AA, Rebecchi IM arin. $M$, et al. In vitro anticoagulant and antioxidant activities of Jatropha gossypiifolia L. (Euphorbiaceae) leaves aiming therapeutical applications. BMC Complement Altern Med, 2014 Dec 20;14(1):405. https://doi.org/10.1186/1472-6882-14-405 PMid:25328027 PMCid:PMC4210492

15. Halim A, Samama MM, Mendell J. Ex vivo reversal of the anticoagulant effects of edoxaban. Thromb Res, 2014 Oct;134(4):909-13. https://doi.org/10.1016/j.thromres.2014.07.036 PMid:25179520

16. Mitchell JA, Akarasereenont P, Vane JR. Selectivity anti-inflammatory, 1994;90(December):11693-7. https://doi.org/10.1073/pnas.90.24.11693 PMid:8265610 PMCid:PMC48050

17. de Craen AJM, Di Giulio G, Lampe-Schoenmaeckers AJEM, Kessels AGH, Kleijnen J. Analgesic efficacy and safety of paracetamol-codeine combinations versus paracetamol alone: a systematic review. BMJ, 1996 Aug 10;313(7053):321-5. https://doi.org/10.1136/bmj.313.7053.321 PMid:8760737 PMCid:PMC2351742

18. Lopes RD, Horowitz JD, Garcia DA, Crowther MA, Hylek EM. Warfarin and acetaminophen interaction: a summary of the evidence and biologic plausibility. Blood, 2011 Dec 8;118(24):6269-73. https://doi.org/10.1182/blood2011-08-335612 PMid:21911832 PMCid:PMC5524527

19. Dakheel S. Low Doses of Acetaminophen Prolonged Prothrombin Time and Increased International Normalized Ratio in Patients Receiving Long-Term Therapy. Clin Exp Pharmacol, 2015;05(05). https://doi.org/10.4172/21611459.1000187

20. Akinmoladun AC, Oguntunde KO, Owolabi LO, Ilesanmi OB, Ogundele JO, Olaleye MT, et al. Reversal of acetaminophen-generated oxidative stress and concomitant hepatotoxicity by a phytopharmaceutical product. Food Sci Hum Wellness, 2017 Mar;6(1):20-7. https://doi.org/10.1016/j.fshw.2016.11.001

21. Gray T, Hoffman RS, Bateman DN. Intravenous paracetamol - an international perspective of toxicity. Clin Toxicol, 2011 Mar 28;49(3):150-2. https://doi.org/10.3109/15563650.2011.568491 PMid:21443426 
22. Brotman DJ, Girod JP, Posch A, Jani JT, Patel JV, Gupta M, et al. Effects of short-term glucocorticoids on hemostatic factors in healthy volunteers. Thromb Res, 2006 Jan;118(2):247-52. https://doi.org/10.1016/j.thromres.2005.06.006 PMid:16005496

23. Barettino $D$, Masiá $S$, Montó $F$, Pérez $P$, Ocon PD, Moreno $L$, et al. Glucocorticoids as modulators of expression and activity of Antithrombin ( At ): Potential clinical relevance. Thromb Res, 2015;135(1):183-91. https://doi.org/10.1016/j.thromres.2014.10.026 PMid:25466848

24. Calao A, Pivonello R, Faggiano A, et al. Persistence of increased cardiovascular risk in patients with cushing's disease after five years of successful cure. J Clin Endocrinol Metab, 1999;84(8):2664-72. https://doi.org/10.1210/jcem.84.8.5896 PMid:10443657

25. Koutroumpi S, Spiezia L, Albiger N, et al. Thrombin generation in Cushing's Syndrome: do the conventional clotting indices tell the whole truth? Pituitary, 2014 Feb 14;17(1):68-75. https://doi.org/10.1007/s11102-0130467-3 PMid:23408210

26. von Känel R, Mausbach BT, Kudielka BM, Orth-Gomér K. Relation of morning serum cortisol to prothrombotic activity in women with stable coronary artery disease. J Thromb Thrombolysis, 2008;25(2):165-72. https://doi.org/10.1007/s11239-007-0035-7 PMid:17562129

27. Sneeboer MMS, Hutten BA, Majoor CJ, Bel EHD, Kamphuisen PW. Oral and inhaled corticosteroid use and risk of recurrent pulmonary embolism. Thromb Res, 2016;140:46-50. https://doi.org/10.1016/j.thromres.2016.02.010 PMid:26897283

28. Isidori AM, Minnetti M, Sbardella E, Graziadio C, Grossman AB. Mechanisms in Endocrinology: The spectrum of haemostatic abnormalities in glucocorticoid excess and defect. Eur J Endocrinol, 2015 Sep;173(3):R101-13. https://doi.org/10.1530/EJE-15-0308 PMid:25987566

29. El-din MMG, Yassin NA. Blood Coagulation Changes in Response to Dexamethasone in the Normal Rat., 1994;62(3):625-30.

30. Chen G, Fei X, Ling J. The Effects of Aminoglycoside Antibiotics on Platelet Aggregation and Blood Coagulation. Clin Appl Thromb, 2012 Sep 12;18(5):538-41. https://doi.org/10.1177/1076029611430955 PMid:22327814

31. Dinev T, Hubenov H, Lashev L, Physiology V, Zagora S. Effects of Aminoglycoside and Aminocyclitol Antibiotics on Blood Coagulation in Goats, 2006;9(4):293-7.

$\diamond \diamond \diamond \diamond \diamond \diamond \diamond$

http://www.ejgm.co.uk 